\title{
Construcción de caminos y reformismo ilustrado: fundamentos económicos y políticos en el caso chileno en el siglo XVIII*
}

\author{
Road Building and Enlightened Reformism: \\ Economic and Political Foundations \\ in $18^{\text {th }}$ Century Chile
}

\author{
María Carolina Sanhueza Benavente \\ ORCID iD: https://orcid.org/0000-0003-3705-1613
}

Pontificia Universidad Católica de Chile, Santiago, Chile

Este artículo plantea que los caminos construidos en Chile en la segunda mitad del siglo XVIII respondieron a una política vial que fue impulsada por los Borbones. Si bien estos proyectos surgieron desde instancias locales, lograron materializarse cuando coincidieron con los objetivos reformistas e imperiales de la Monarquía hispana. Entre ellos, acentuar el control territorial sobre sus dominios en un contexto de cambios geopolíticos, así como maximizar sus recursos económicos bajo los postulados de las ideas ilustradas.

PALABRAS Clave: caminos; política vial; cartografía; comunicación; circulación; Ilustración; Reformas Borbónicas; Chile.

This article proposes that the roads built in Chile in the second half of the $18^{\text {th }}$ century were the result of an infrastructure policy put forward by the Bourbons. Although these construction projects were first envisaged by local authorities, they only materialized when they coincided with the reformist and imperial objectives of the Spanish Monarchy. These objectives included, among others, establishing a more rigid control over its domains. These reforms were developed in a context of geopolitical changes and they aimed at maximizing the extraction of economic resources under the postulates of the Enlightened ideas.

KeYwords: Roads; Road Policy; Cartography; Communication; Circulation; Enlightenment; Bourbon Reforms; Chile.

Copyright: (C) 2021 CSIC. Este es un artículo de acceso abierto distribuido bajo los términos de la licencia de uso y distribución Creative Commons Reconocimiento 4.0 Internacional (CC BY 4.0).

* Este artículo ha sido financiado por la Agencia Nacional de Investigación y Desarrollo (ANID), Beca de Doctorado Nacional/2019-21191218, Chile. Agradezco a José Ragas, Lucrecia Enríquez y a los evaluadores por sus comentarios y recomendaciones que sirvieron para mejorar este texto. 
La red de caminos en Chile poco cambió hasta el período borbónico, cuando se abrieron y mejoraron tres vías importantes: la de Santiago a Valparaíso, la de Valdivia a Chiloé y el paso trasandino por Uspallata, que conectaba Aconcagua con Mendoza. Pese a su relevancia, las tres han sido abordadas en función de otras temáticas ${ }^{1}$ o bien, de forma independiente entre sí, refiriéndose a cada una de ellas de forma singular con su propia historicidad. ${ }^{2}$ Pocos trabajos ahondan en elementos contextuales de mayor alcance temporal y los argumentos ideológicos que propiciaron su realización. Tampoco las consideran como objetos de análisis en sí mismos y como instrumentos económico-políticos al servicio del poder imperial.

Con el propósito de comprender cómo estos caminos actuaron en beneficio de la Corona española y la interacción entre el poder imperial y el local en el Chile borbónico, este artículo plantea que los proyectos viales deben estudiarse de forma integrada. Solo cuando los caminos se analizan en conjunto, extendiéndose los marcos temporales y espaciales, es posible entender la racionalidad detrás de su construcción y por qué en Chile se desarrollaron en el último tercio del siglo XVIII, después de dos siglos de abandono vial. El que las tres vías referidas se hayan desarrollado en dicho período se explica por la convergencia de un ambiente político e intelectual propiciado por la Ilustración y los cambios geopolíticos occidentales. Por una parte, los caminos tuvieron un rol estratégico para agilizar las comunicaciones y acentuar la presencia efectiva sobre ciertos territorios, como ocurrió con el de Valdivia-Chiloé y el paso trasandino. Por otra, el afán ilustrado de potenciar la economía y conectar mercados fue evidente en el camino Santiago-Valparaíso, pero también en el paso de Uspallata. Además, estos caminos respondieron a circunstancias y necesidades regionales, en un proceso impregnado de tensiones y colaboraciones con los actores locales. Sin embargo, su materialización siguió las pautas viales impulsadas por los Borbones en la península, uniéndose los tres proyectos bajo un fundamento ideológico común, alineado con la lógica del reformismo ilustrado.

El texto se organiza en dos secciones. La primera aborda la política vial borbónica y cómo se extendió hacia las colonias americanas. La segunda muestra su manifestación en la capitanía general de Chile, a través de los tres proyectos mencionados al inicio de esta presentación.

1 Greve, 1938. Urbina Carrasco, 2009. Méndez Beltrán, 2009.

2 Martínez, 1962; 1969. Pinto Vallejos, 1976. Molina Verdejo, 2000. Urbina Carrasco, 2005. 


\section{De Europa a América: los caminos en el reformismo ilustrado del siglo XVIII}

Mejorar la conectividad terrestre fue parte de una política imperial iniciada en la Europa del siglo XVIII, cuando los caminos experimentaron un giro importante a nivel teórico y práctico. La inédita relevancia que cobraron las consideraciones económicas con la Ilustración se vio reflejada cuando la generación de riqueza se convirtió en un aspecto prioritario entre las monarquías absolutas, concibiéndose como un pilar determinante para el devenir de los Estados y la consolidación de su poder. Esto proporcionó fundamentos ideológicos para el fomento de obras públicas, las que ocuparon un lugar privilegiado en los planes monárquicos como instrumentos para el ansiado crecimiento económico. ${ }^{3}$ Canales, puertos, puentes o caminos servirían para incentivar la producción, la industria y el comercio, pero también para controlar territorios con fines administrativos y militares con miras a una mayor centralización, en un contexto de fuerte competencia mundial. Potencias como Rusia, Francia e Inglaterra fortalecieron las comunicaciones terrestres tras crear centros especializados y aplicar políticas que incentivaron mejoras viales. Pedro I y Catalina la Grande promovieron la construcción de caminos para consolidar sus conquistas territoriales, conectando poblados y nuevos puertos, a modo de expandir la autoridad imperial hacia zonas apartadas. ${ }^{4}$ En Gran Bretaña, los turnpike trusts se complementaron con un fuerte fomento estatal para construir carreteras desde la década de 1720, mejorando el transporte terrestre y permitiendo una mayor presencia del Estado sobre su territorio. ${ }^{5}$ Para el gobierno francés, los caminos se instalaron como un asunto de interés nacional, los que se modernizaron a partir de los años de 1730 para reactivar las actividades económicas de su territorio, centralizar y hacer más efectiva su administración. ${ }^{6}$ Igualmente, la creación de la École des Ponts et Chausseés en 1747 se erigió como un ejemplo a imitar en la formación de cuerpos especializados en vialidad.

3 Crespo Delgado, 2015, 38.

4 Busch, 2008.

5 Aunque los turnpike trusts, un sistema de administración de peajes otorgados a privados para financiar obras viales, datan de mediados del siglo XVII, a partir del último tercio del XVIII se expandieron notablemente. Bogart, 2005. Guldi, 2012.

6 Esto se complementó con un mapeo exhaustivo de las rutas de Francia que también permitió una mejor comprensión y manejo del territorio. Blond, 2013. 
La monarquía española no se marginó de estas ideas y procesos. Imbuida de un carácter práctico y utilitario que se combinó con anhelos políticos, la acción estatal se sustentó sobre la base de principios seculares como la prosperidad y la felicidad pública. ${ }^{7}$ Ellos pasaron a ser el norte de las políticas de Estado durante el reformismo borbónico, cuando la Corona intentaba reposicionarse en el concierto internacional. Políticos y tratadistas como Gerónimo de Uztáriz y Bernardo Ward remarcaron la relevancia de mejorar los caminos para impulsar la alicaída economía, lo que decantó en el desarrollo de una política de Estado que potenciaba las comunicaciones terrestres. ${ }^{8}$ Se apuntó a varios flancos que incluían medidas administrativas, legales, formativas y una puesta en práctica con obras concretas. El Estado adquirió un rol preponderante, lo que representó un cambio sustancial con respecto al período Habsburgo, cuando los caminos fueron descuidados a cargo de los particulares y las mestas. ${ }^{9}$

Las primeras disposiciones se remontan a la Ordenanza de Intendentes de 1718. Aplicada solo en la península, incorporó instrucciones para mejorar los caminos, puentes y velar por su comodidad y seguridad. ${ }^{10}$ Según Menéndez Pidal, por primera vez se intentó dar soluciones integrales a los problemas que aquejaban a las vías españolas, mediante un plan de reparación de la red que fuera en provecho de todos. ${ }^{11}$ Estas pautas se reiteraron en la nueva Ordenanza de 1749, sumándose otras normas emitidas por Carlos III. ${ }^{12}$ Como la política vial borbónica apuntó a integrar las ambiciones y proyectos de la monarquía con un plan de ejecución real, también se crearon cuerpos especializados en este tipo de obras para aplicar la teoría y las medidas administrativas. La fundación del Cuerpo de Ingenieros Militares en 1711 fue un paso significativo, porque establecía un órgano técnico-profesional que fue relevante para llevar a cabo la política vial en la península y, más tarde, en América. A fines de siglo, la creciente importancia dada a las comunicaciones para el comercio y las necesidades de contar con un cuerpo más especializado impulsaron desde instancias gubernamentales la

7 Pietschman, 1996, 24-30. Kuethe y Andrien, 2018, xxii. Crespo Delgado, 2015, 35-38.

8 Mientras que Ustáriz alabó los adelantos que llevó a cabo Luis XIV de Francia en esta materia y destacó su utilidad para el comercio, los caminos fueron un tema transversal en el Proyecto económico de Ward. Ustáriz, 1742, 61 y 40. Ward, 1779.

9 Menéndez Pidal, 1951, 83.

10 Ordenanza de 4 de julio de 1718 para el establecimiento, e instrucción de Intendentes..., 1720 , arts. 47-51.

11 Menéndez Pidal, 1951, 115-116.

12 Ordenanza de 13 de octubre de 1749 para el restablecimiento, é instruccion de Intendentes..., 1749, 11-13. Terán, 1984, 64-65. 
Escuela de Caminos, Canales y Puertos entre 1799 y 1802, a semejanza de su par francés. ${ }^{13}$

Aunque a mediados de siglo la red vial permanecía en un estado deficitario, el tema ya estaba instalado entre los hombres de Estado. En su Tratado dirigido a Fernando VI, Manuel Fernández de Mesa señaló que el cuidado de los caminos era uno de los asuntos «que más conducen para el provecho público, y particular; como que en él estriba facilitar el gobierno, el saber, las riquezas, el comercio, y cuanto hay de consideración entre los mortales». ${ }^{14}$ Hacia 1757, el conde de Aranda propuso hacer «nuevos y magníficos caminos» en toda la península, encargando a fray Martín Sarmiento un estudio que sirviera para justificar y evaluar las probabilidades de tal empresa. ${ }^{15}$ En sus Apuntamientos argumentó de forma transversal que los caminos eran útiles «para todo y para todos», pues con ellos se multiplicaría la población, los ganados, frutos y plantíos «que son los cuatro elementos de un estado feliz». ${ }^{16}$ En su escrito estaban presentes las cuestiones económicas y un plan territorial que se adecuaba a la centralización del ejercicio del poder pretendido por la monarquía. ${ }^{17}$ Por una parte, las obras viales sentarían las bases para elaborar mapas más precisos, permitiendo conocer en detalle el territorio español. Por otra, propuso una red de caminos radiales que salieran de Madrid hacia los extremos de la península, centralizando el territorio en lo geográfico, así como en lo político, consolidando la primacía de su capital. La idea se validó con el Real Decreto de 1761 y dio pie a que se construyeran caminos hacia Cataluña, Andalucía, Galicia y Valencia en las últimas décadas de la centuria. ${ }^{18}$

Estos planes de desarrollo vial, ideados por los Borbones inicialmente para el territorio peninsular, se volcaron en actuaciones más concretas a partir del ascenso de Carlos III, expandiéndose hacia tierras americanas.

13 Sáenz Ridruejo, 2015, 23-24.

14 Fernández de Mesa y Moreno, 1755, palabras iniciales. La ortografía de las citas textuales usadas en este artículo se modernizó para facilitar su lectura.

15 Sarmiento presentó su escrito, fechado el 21 de julio de 1757, como un borrador que serviría de modelo para otros estudios más acabados en la materia. Sarmiento, 1789, 12.

16 Ibidem, 5 y 153.

17 Reguera Rodríguez, 1999, 479 y siguientes.

18 El espíritu del decreto de Carlos III se deja ver en sus primeras palabras: «Tengo considerado, que uno de los estorbos capitales de la felicidad pública de estos mis reinos es el mal estado en que se hallan sus caminos...». «Copia del Real Decreto expedido para hacer caminos rectos, y sólidos en España, que faciliten el comercio de unas Provincias á otras, dando principio por los de Andalucia, Cathaluña, Galicia, y Valencia», Aranjuez, 12 de junio de 1761, Archivo Histórico de la Nobleza, Toledo, Condado de Priego, c. 16, d. 19. Reguera Rodríguez, 1999, 497-503. Terán, 1984. Menéndez Pidal, 1951, 123-130. 
En estas latitudes surgieron varios proyectos que respondieron a objetivos particulares de cada localidad, pero que se legitimaron con fuerza con el despotismo ilustrado. El traspaso de esta política vial hacia el Nuevo Mundo vino de la mano con los cambios geopolíticos provocados por la guerra de los Siete Años y la pérdida de La Habana en 1762, cuando se reformuló la relación entre la monarquía y las Indias hacia una de mayor subordinación y dependencia. Al concebirse como colonias a las que se debían sacar el máximo provecho, las nuevas reformas apuntaron a conservar las posesiones en ultramar, fortaleciendo el control efectivo sobre el territorio. Como los caminos posibilitaban un mejor despliegue del poder real, la Corona promovió nuevos proyectos y avaló los que surgían desde instancias locales. El régimen de intendencias implementado en la década de 1780 centralizó la administración sobre estos asuntos al incorporar competencias para proteger los territorios de otras naciones y fomentar la economía y el comercio. A los intendentes se les instruyó tender nuevos caminos y arreglar los existentes para potenciar la explotación y extracción de los recursos americanos. ${ }^{19}$ Consolidar la conectividad terrestre era fundamental para el flujo expedito de las comunicaciones y fortalecer la colonización, sobre todo en aquellas zonas con baja presencia de la autoridad imperial. Regiones periféricas e interiores, como la Nueva Granada, la frontera norte novohispana o el sur de Chile eran vulnerables ante incursiones indígenas y extranjeras, por lo que desarrollar una red de caminos aseguraba la articulación de los territorios y la cohesión de los espacios mal controlados. A su vez, la apertura de vías por estos lugares, considerados como inhóspitos y salvajes, fue concebida como parte de un proyecto civilizador que llevaría a la integración de sus habitantes. Como los caminos se pensaron como un instrumento material que ayudaría a acentuar el control económico y territorial, dichos propósitos se complementaron con los requerimientos defensivos, ya que los enclaves estratégicos como puertos o fuertes requerían de vías para su aprovisionamiento y despliegue militar. ${ }^{20}$

De esta manera, la Ilustración, el nuevo escenario geopolítico y el carácter que adquirió América para los propósitos de la monarquía justificaron

19 La Ordenanza establecía que se informara sobre todos aquellos medios útiles para la industria y el comercio, incluyendo información relevante sobre caminos y puentes que pudieran mejorarse. Real Ordenanza para el establecimiento é instruccion de Intendentes..., 1782, arts. 54, 60-63.

20 Este fue el caso de la ruta que unía México y Veracruz, cuya idea de habilitarla para el tránsito carretero surgió por el aumento del tráfico comercial, así como por las dificultades experimentadas en el envío de tropas y pertrechos para la defensa del puerto, en el marco de la guerra con Inglaterra (1779-1783). Valle Pavón, 2007, 446. 
la realización de obras viales, allanando la senda para trazarlas en estas latitudes. Desde Nueva España a la capitanía general de Chile proliferaron los proyectos, aunque solo algunos llegaron a concretarse, como los de México-Veracruz, México-Toluca, Lima-Callao y los que analizamos a continuación. ${ }^{21}$ La idea de construir caminos carreteros para maximizar la extracción de los recursos se mantuvo presente entre las autoridades, quienes se referían a ellos como las venas del imperio, por donde fluían las riquezas de sus territorios. Por ejemplo, Ambrosio O'Higgins «comparaba a la capital con el corazón y a los caminos reales que de ella salen con las grandes arterias que llevan la sangre». ${ }^{22}$ Precisamente, uno de los focos fue proyectar carreteras para optimizar el tránsito entre los puertos y centros administrativos, así como franquear el paso desde y hacia el exterior del continente. La fórmula para desarrollar infraestructuras viales en América, sin que se viera afectado el real erario, fue delegar su construcción a órganos locales, como los cuerpos municipales o los consulados de comercio. ${ }^{23}$ La estrategia de cooperación de la monarquía con las elites criollas rindió frutos en algunos casos de habilitación de caminos carreteros, toda vez que fue en mutuo beneficio. Se pensaba que sus positivos efectos sobre el transporte estimularían el comercio y la producción, dejando réditos a los locales. Todo ello sin dejar de lado los objetivos perseguidos por la metrópoli, tanto los económicos como los de gobierno y felicidad pública. Las iniciativas viales que surgieron en América encajaron con los planes de los Borbones ${ }^{24}$ aunque no estuvieron exentas de conflictos entre las autoridades americanas y propietarios particulares al momento de definir los trazados de las rutas. Estos fueron los casos de los caminos Caracas-La Guaira y México-Veracruz, donde se impusieron los intereses privados sobre los de los agentes gubernamentales. ${ }^{25}$

21 Otros proyectos que no lograron materializarse fueron los caminos de la Nueva Guatemala al golfo de Honduras y el de Caracas-La Guaira. Serrera, 1992.

22 Thomas, 1914, 135.

23 En 1793 se crearon nuevos consulados en Caracas y Guatemala, en 1794 en Buenos Aires y La Habana y en 1795 en Santiago de Chile, Cartagena, Guadalajara y Veracruz. Todos ellos se sumaron a los ya existentes de Ciudad de México y Lima. Paquette, 2007, 271.

24 Ibidem, 274-278.

25 El primero lo propuso el recién creado Consulado de Caracas, siendo aprobado por la Corona. El proyecto se frenó por la oposición de los hacendados, que no querían ver mermadas sus propiedades con el nuevo trazado, y por los conflictos de autoridad suscitados con el gobernador, quien no reconocía las atribuciones de la corporación en materia de comunicaciones. En cambio, el segundo proyecto se materializó entre 1796 y 1810, luego de años de discusión entre el segundo conde de Revillagigedo y los miembros del consulado mexicano, quienes se impusieron con un recorrido que favorecía sus negocios particulares. Para más detalles, véanse Serrera, 1992, 88-95; Valle Pavón, 2001; 2007. 
La expansión del escenario bélico y de los circuitos comerciales al Atlántico sur en la segunda mitad del siglo XVIII forjó la instancia para concretar mejoras viales en los márgenes meridionales del imperio, incluyendo la capitanía general de Chile. Mientras que la amenaza extranjera impulsó acciones gubernativas, el incremento de la actividad comercial demandó mejores condiciones materiales para el tráfico de bienes. Para los Borbones, el desarrollo vial se concibió como una forma de dar respuesta a estos problemas y que, a la larga, ayudaría a asentar el control efectivo de la Corona sobre sus territorios e incrementar sus recursos económicos.

En Chile los caminos se desatendieron por largo tiempo. Con la fundación de ciudades durante los gobiernos de Manso de Velasco (1737-1744) y Ambrosio O'Higgins (1788-1796), el Camino Real a la Frontera comenzó a consolidarse como el principal eje longitudinal. Las nuevas villas que se crearon al alero de la ruta quedaron enlazadas entre sí a una jornada de viaje. ${ }^{26}$ Sin embargo, esto no influyó en su calidad ni en el interés del gobierno central por esta vía. Sus reparaciones fueron parciales, limitándose a despejar ciertos tramos a petición de autoridades locales. ${ }^{27}$ Paradójicamente, como cumplía con su objetivo de comunicación interregional, quedó relegado de un plan sistemático de mejoras. En cambio, otros proyectos llamaron la atención de la monarquía, la cual respaldó su ejecución, aprobando iniciativas locales, manteniéndose a la expectativa de sus avances y brindando reconocimientos formales a quienes lograron llevarlos a cabo. La política vial borbónica se manifestó en Chile en los caminos Santiago-Valparaíso, el paso trasandino por Uspallata y Valdivia-Chiloé, en donde confluyeron el afán económico ilustrado, las necesidades locales y las geopolíticas del imperio.

\section{El camino Santiago-Valparaíso (1791-1796)}

$\mathrm{Al}$ igual que en otras latitudes, llegar a la costa fue imprescindible para ponerse en contacto con otros lugares. Valparaíso era la puerta principal de la capitanía general, el nodo que articulaba la capital con el Pacífico y, por lo tanto, con el Callao, Lima y el resto de las provincias chilenas. Como el mal estado de los caminos interiores dificultaba el tránsito terrestre, la ruta marítima fue la alternativa para cubrir amplias distancias. Esto hizo del camino

26 Sanhueza Benavente, 2018, 30.

27 Ibidem, 87-89. 
Santiago-Valparaíso un eje fundamental para el gobierno interior, ya que enlazaba la cabecera gubernamental con el resto de sus territorios y la capital del virreinato. No obstante, fueron las consideraciones económicas las que primaron a la hora de establecer un camino más expedito hacia el puerto. En la segunda mitad del siglo XVIII, el comercio exterior se expandió con la intensificación del tráfico por el cabo de Hornos y el afianzamiento progresivo de los navíos de registro. Desde Valparaíso se extraían los bienes de las tierras circundantes a Santiago y de otras economías regionales como el norte minero y los valles agropecuarios del sur. ${ }^{28} \mathrm{~A}$ los cambios anteriores se sumó la liberalización comercial con distintos puertos españoles en 1778 que, pese a los beneficios que reportó para el comercio y la población, provocó efectos desestabilizadores en la economía local. El exceso de productos europeos saturó el mercado chileno y la baja de los precios perjudicó a comerciantes chilenos y limeños. ${ }^{29}$ Las quejas elevadas al gobierno central dieron origen a la real orden de 8 de octubre de 1788, que solicitaba a los consulados y autoridades americanas informar sobre el estado del comercio. En respuesta, el gobernador Ambrosio O'Higgins pidió informes a comerciantes locales, quienes confirmaron el panorama y sus principales consecuencias, como la disminución de circulante y del precio de las mercancías, la quiebra de los negocios y la ruina de las industrias. ${ }^{30}$

Bajo este escenario y convencido de los beneficios de la actividad mercantil para el país, O'Higgins propuso al cabildo de Santiago la construcción de un camino carretero hasta el puerto de Valparaíso. El ayuntamiento lo aprobó el 17 de mayo de 1791, «teniendo presente los daños y pérdidas que hasta lo presente ha experimentado el público por la falta de este camino». ${ }^{31} \mathrm{La}$ frecuencia con que se deterioraban las mercancías por el mal estado de las rutas justificaba la necesidad de una vía más cómoda, directa y expedita, por lo que el cabildo le expresó «las más eficaces y ardientes gracias». ${ }^{32}$

Por entonces, el tráfico hacia el puerto se hacía principalmente a lomo de mulas por dos vías. Una que corría por el valle de Melipilla y soportaba

28 Carmagnani, 2001, 47-97. Cavieres Figueroa, 2003, 34.

29 Villalobos R., 1990, 100-111. Jocelyn-Holt, 1992, 125-126.

30 O’Higgins remitió a la corte los informes de Domingo Díaz de Salcedo y Muñoz, Francisco Javier Errázuriz, José Urrutia Mendiburu y Tomás Delfín. Más detalles sobre esto, así como una reproducción de dichos textos en Villalobos R., 1990, 106-111 y 284-324. 200-201.

31 Acta del cabildo de Santiago, Santiago, 17 de mayo de 1791, en Cabildo de Santiago, 1990,

32 Ibidem, 201. 
un tránsito limitado de carretas, pero daba un largo rodeo por el sur. La otra, que pasaba por Curacaví y Casablanca, era más directa, aunque accidentada, ya que se debía atravesar las empinadas cuestas de Lo Prado y Zapata. Tras optar por esta última opción, los trabajos se iniciaron el mismo año de 1791 con un financiamiento de peaje aprobado por cabildo. ${ }^{33}$ La medida gravó a los transportistas, porque estos sacaban la mayor ventaja al ahorrarse los deterioros de sus medios de transporte y productos. De hecho, la legislación indiana expresaba que los costos de las obras viales debían ser asumidos y repartidos «entre los que recibieren el beneficio, y más provecho». ${ }^{34}$ La empresa era significativa, pues debía intervenirse una topografía con pendientes pronunciadas sobre las que había que establecer un diseño zigzagueante (Fig. 1). Por su complejidad, las obras fueron dirigidas por ingenieros militares como Pedro Rico, Agustín Caballero y el arquitecto Joaquín Toesca, mientras que su ejecución fue delegada a Manuel de la Puente que también se desempeñó en otros trabajos viales. ${ }^{35}$

Sin embargo, desde 1792 la obra tuvo que sortear las objeciones de José Miguel Prado Covarrubias, dueño de la hacienda por donde pasaba el nuevo camino. Apeló a la Audiencia más de una vez para cambiar el trazado, prometiendo hacerse cargo de la construcción y sus costos, pero O'Higgins estimó que no era de «la calidad y naturaleza que convenía al objeto propuesto de facilitar el comercio de carretas». ${ }^{36} \mathrm{Su}$ oposición se mantuvo durante toda la etapa de ejecución del proyecto y en 1794 acudió directamente al rey, pero sin resultados favorables. Argumentó que sus terrenos serían fragmentados, que los arrieros seguirían transitando por Melipilla, que el costo era excesivo y que demandaría grandes gastos de conservación al real erario. Por último, solicitó indemnizaciones nobiliarias por los daños y agravios que sufrió de parte del gobernador. ${ }^{37}$

33 La contribución fue de 4 reales por carreta cargada, 1/2 real por mula cargada con dos tercios sobre su lomo y la mitad de ello para los vehículos y animales sin mercancías, pero que esperaban recibirlas en el trayecto.

34 «Que se hagan, y reparen puentes, y caminos...», Recopilacion de leyes de los Reynos de las Indias, 1681, vol. II, lib. IV, tít. XVI, ley 1. También, «Que los virreyes puedan mandar abrir caminos...», Ibidem, lib. III, tít. III, ley 53.

35 Los trabajos se iniciaron bajo la dirección técnica de Pedro Rico en 1791, pero debido a una enfermedad fue sustituido por Joaquín Toesca en 1793, a la espera de la llegada de Agustín Caballero. Aunque fue designado en 1792 por los peninsulares para reemplazar a Pedro Rico, no fue sino en 1795 cuando arribó a Chile, haciéndose cargo del proyecto en su última etapa. Pereira, 1965, 175-176 y 187.

36 Ambrosio O’Higgins a Antonio Porlier, Santiago, 16 de noviembre de 1792, Archivo Nacional Histórico de Chile, Santiago (ANH), Capitanía General, vol. 786, ff. 45-46.

37 Donoso, 1941, 231. 


\section{FIGURA 1}

\section{TRAZADO DEL CAMINO SANTIAGO-VALPARAÍSO \\ Y DETALLE DE LA CUESTA ZAPATA}
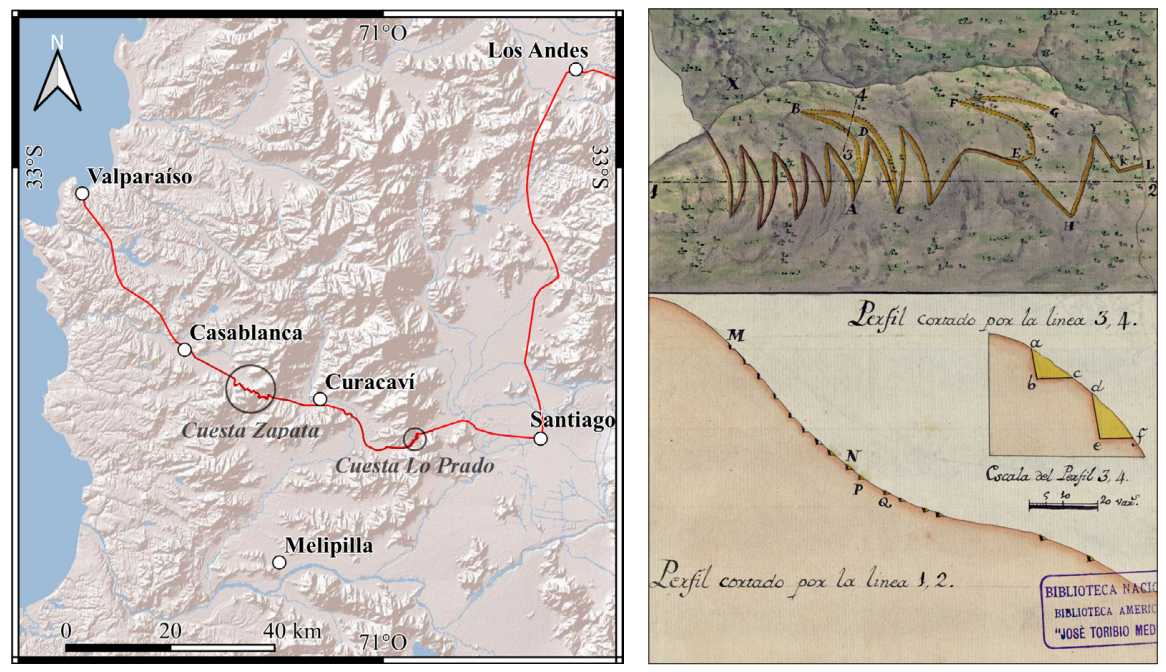

Fuente: Elaboración de José Manuel Lattus, 2021 (izquierda). Detalle de Agustín Caballero, Plano y perfil de la Cuesta Zapata, Santiago, 28 de enero de 1795, Biblioteca Nacional de Chile, Sala Medina, P1-9 (derecha).

La estrategia seguida por Ambrosio O'Higgins para obtener el apoyo peninsular fue mantener informada a la corte, insistir en la utilidad del proyecto, transparentar los intereses individuales del afectado en desmedro de la felicidad pública, así como demostrar que su iniciativa contaba con el respaldo de la población. Desde un inicio recalcó la necesidad de allanar el camino «por donde se hace la mayor, o casi única parte de su comercio de exportación $»^{38}$ e informó en detalle lo ocurrido y todos los procedimientos realizados por él sobre el asunto. Hizo hincapié en que buscó una solución consensuada, acogiendo las inquietudes del hacendado, realizando nuevos reconocimientos del terreno y dándole la oportunidad de que nombrara peritos por su cuenta que estimaran posibles daños: «desde mis primeras

38 Ambrosio O’Higgins a Antonio Porlier, Santiago, 16 de noviembre de 1792, ANH, Capitanía General, vol. 786, f. 44. 
providencias en que declaré la necesidad de construir el camino por un canto de su hacienda, declaré también estar pronto a satisfacer los perjuicios que justificase irrogársele». ${ }^{39} \mathrm{O}$ 'Higgins continuó los trabajos mientras esperaba las instrucciones de la Corona sobre cómo proceder frente a los recursos impuestos por José Miguel Prado a la audiencia. Para ello se amparó en el mandato de 6 de mayo de 1792 «en que ha querido V. E. se le instruya anualmente del progreso que se haga en materia de caminos». ${ }^{40}$ En sus comunicados se refirió a la «obstinación» y «terquedad» de Prado Covarrubias, quien había actuado por medio de «innumerables supercherías» con la finalidad de «frustrar una providencia justa, y conveniente al público, y por solo el placer de hacer oposición al gobierno» ${ }^{41}$ En junio de 1793, la corte aprobó todas las decisiones del gobernador, declarando que «es la voluntad del Rey que en punto de caminos no otorgue el presidente ni admita la Audiencia apelaciones». ${ }^{42} \mathrm{El}$ espaldarazo reconocía las atribuciones de los nuevos intendentes en materia vial. ${ }^{43}$ La copia de la real orden que se le envió a O'Higgins reforzaba su autoridad al respecto y demostraba la seriedad con que se trataban los asuntos viales en la península: «para la aprobación del Rey dé V. S. cuenta de todo a S. M. por este ministerio de mi cargo, con quien inmediata, y exclusivamente se ha de entender V. S. en punto de caminos». ${ }^{44} \mathrm{El}$ respaldo se reafirmó a fines de 1794, cuando se rechazaron las solicitudes que el hacendado elevó directamente a la Corona. ${ }^{45}$

Pese a las dificultades, la obra finalizó hacia 1796. Se logró utilizando los mecanismos establecidos por la administración hispana, provenientes de las Leyes de Indias y del régimen de intendencias. La corte ratificó las atribuciones del gobernador y fue taxativa con que los asuntos de caminos

39 O’Higgins encargó nuevas inspecciones del trazado al catedrático de matemáticas Antonio Martínez de Mata y a Joaquín Toesca, a quienes se unieron el procurador general y José Miguel Prado. Todos, menos este último, concluyeron que el único lugar apropiado para la construcción era el que había designado el ingeniero Pedro Rico en su plan inicial. Ante la negativa de José Miguel Prado de aceptar la decisión, O’Higgins se dirigió personalmente al lugar para zanjar la disputa. Ibidem, ff. 45v y 48v.

40 Ibidem, f. 48.

41 Ambrosio O’Higgins a Eugenio Llaguno y Amírola, Santiago, 13 de mayo de 1795, ANH, Capitanía General, vol. 786, f. 99-99v.

42 Pedro Acuña y Malvar a los señores regente y oidores de la Real Audiencia de Chile, real orden del 4 de junio de 1793, ANH, Capitanía General, vol. 742, f. 123-123v.

43 Real Ordenanza para el establecimiento é instruccion de Intendentes..., 1782, arts. 60-63.

44 Pedro Acuña y Malvar al señor presidente de Chile, real orden del 4 de junio de 1793, ANH, Capitanía General, vol. 742, f. 124.

45 Cuando Ambrosio O’Higgins acusó recibo de la orden de 2 de diciembre de 1794, señaló que desconocía dichas solicitudes y que, ante el fallecimiento de José Miguel Prado, daría a conocer la resolución a sus herederos. Ambrosio O’Higgins a Eugenio Llaguno y Amírola, Santiago, 13 de mayo de 1795, ANH, Capitanía General, vol. 786, ff. 98v-99v. 
debían resolverse por vía reservada, en comunicación con los secretarios del despacho. Sus respuestas sobre el conflicto no dieron cabida a impedimentos basados en el interés individual y que fueran en perjuicio de la felicidad pública. La resolución de la Corona se justificó por la utilidad del proyecto y porque contaba con una amplia aprobación local. José Miguel Prado no contaba con el soporte político ni de los grupos económicos, algo que difiere de las fuertes oposiciones interpuestas en otras partes de América, como el camino México-Veracruz, en donde se impuso el trazado propuesto por los comerciantes. En cambio, la iniciativa chilena sí tuvo el respaldo del cabildo, de algunos miembros de la Audiencia, de los cuerpos técnicos involucrados, así como de los comerciantes que vieron una oportunidad para sus negocios. ${ }^{46}$ Estos últimos acogieron el proyecto desde sus inicios por las comodidades y seguridad que proporcionaba y porque «el beneficio [era] común a todos los interesados en el tráfico». ${ }^{47}$ No fue sino en 1795 cuando se creó el Tribunal del Consulado santiaguino, una vez terminado el grueso de la obra, por lo que dichas mejoras se realizaron sin intervención de este órgano. Sin embargo, ese mismo año los comerciantes evaluaron cuán calificado estaba el gremio para emprender estos trabajos, considerando que «S. M. ha hecho privativo del Gobierno este negocio».48 Aunque el fomento de las obras públicas que ayudaran a la actividad mercantil estaba entre sus prerrogativas, ${ }^{49}$ señalaron que abrir nuevos caminos era un asunto de Estado. Se desvincularon de la materia, añadiendo que su participación debía limitarse a deliberar y proponer para que la autoridad política resolviera acorde a los canales oficiales: «es un negocio que debe parecer reservado a la Superioridad del Gobierno. Acaso este descubriría inconvenientes contrarios a la seguridad del Estado, donde el comercio no veía sino las ventajas de un menor flete». ${ }^{50}$ Aunque la voluntad gubernamental se impuso en

46 El gobernador comunicó a los peninsulares que su decisión fue interpretada en Santiago como un triunfo, añadiendo que «nunca he visto un júbilo más ardiente, ni más general». En el último reconocimiento que hizo de la obra, lo acompañaron el obispo y más de treinta vecinos de la capital y apuntó que «nada puede compararse a la satisfacción que a su vista ha recibido este pueblo, y demás gentes de nuestra compañía». Ambrosio O'Higgins a Pedro Acuña y Malvar, Santiago, 17 de octubre de 1793, ANH, Capitanía General, vol. 786, f. 72-72v.

47 Juez de comercio a Ambrosio O'Higgins, Santiago, 1 de junio de 1791, ANH, Tribunal del Consulado, vol. 5, f. 18.

48 José Santiago Portales [y otro] a los señores del Tribunal del Consulado, Santiago, 29 de octubre de 1795, ANH, Tribunal del Consulado, vol. 5, f. 54v.

49 Estas se hallan en los arts. 22 y 23 del Reglamento del Real Tribunal del Consulado de Santiago. Real cédula de 26 de febrero de 1795, ANH, Capitanía General, vol. 744, ff. 28-51v.

50 José Santiago Portales [y otro] a los señores del Tribunal del Consulado, Santiago, 29 de octubre de 1795, ANH, Tribunal del Consulado, vol. 5, f. 55. 
el camino de Santiago a Valparaíso, solo fue posible porque contó con el apoyo de una población que veía alineados sus intereses con la política de fomento vial borbónica.

\section{El paso de la cordillera de los Andes por Uspallata (1765-1791)}

Abrir la cordillera de los Andes al tránsito permanente fue una preocupación durante la segunda mitad del siglo XVIII. Santiago mantuvo un frecuente intercambio comercial con las provincias trasandinas, en donde Mendoza actuó como punto de articulación y redistribución de mercancías. Este comercio se había incrementado de forma sostenida a partir de la década de 1730, cuando el comercio legal e ilícito se extendió hasta la vertiente atlántica ${ }^{51}$ El cambio de los circuitos tradicionales incidió en que el Río de la Plata cobrara mayor preponderancia dentro del sistema colonial, de modo que mantener una comunicación más fluida entre ambas laderas de la cordillera se hizo patente ya hacia los años sesenta. La vía terrestre era suplementaria a la marítima por el cabo de Hornos y constituyó una alternativa para los tiempos de crisis. ${ }^{52}$ De las rutas que se usaban, la que conectaba Mendoza con el valle del Aconcagua (vía Uspallata-Las Vacas-Las Cuevas) fue la preferida por los funcionarios de gobierno y por quienes transportaban efectos con recuas de mulas (Fig. 2).

Si bien esta vía enlazaba directamente Santiago y el valle de Aconcagua con Mendoza y la provincia de Cuyo, se extendió como una ruta bioceánica que conectaba los puertos de Buenos Aires y Valparaíso de forma terrestre. Como desde aquí se prolongaba por mar hasta el Callao y Lima, la ruta rearticulaba los centros administrativos de la América meridional, de modo que las consideraciones de gobierno tuvieron un peso importante en sus mejoras. El paso por Uspallata representaba serias dificultades por sus condiciones geográficas a más de 3.200 metros de altitud, siendo frecuentes los accidentes durante la travesía. El hecho de que parte de las cargas transportadas se perdieran o averiaran y que fuera transitable solo durante la temporada estival fue lo que llevó a plantear su refacción generalizada. No se trató de un

51 Carmagnani, 2001, 60-64.

52 Según Carmagnani, el tráfico mercantil desde Buenos Aires se hacía por la vía cordillerana solo cuando la ruta marítima se veía comprometida por la guerra o cuando los comerciantes españoles estimaban un estrecho margen de ganancia. De todos modos, hay que considerar que este comercio siempre estuvo mediado por las restricciones impuestas para el comercio interregional indiano y por la presión que ejercía el contrabando a través de la colonia de Sacramento. Ibidem, 88. Villalobos R., 1990, 36-56 y $71-100$. 


\section{FIGURA 2}

\section{REPRESENTACIÓN CARTOGRÁFICA DE LA RUTA TRASANDINA DESDE VALPARAÍSO A BUENOS AIRES}

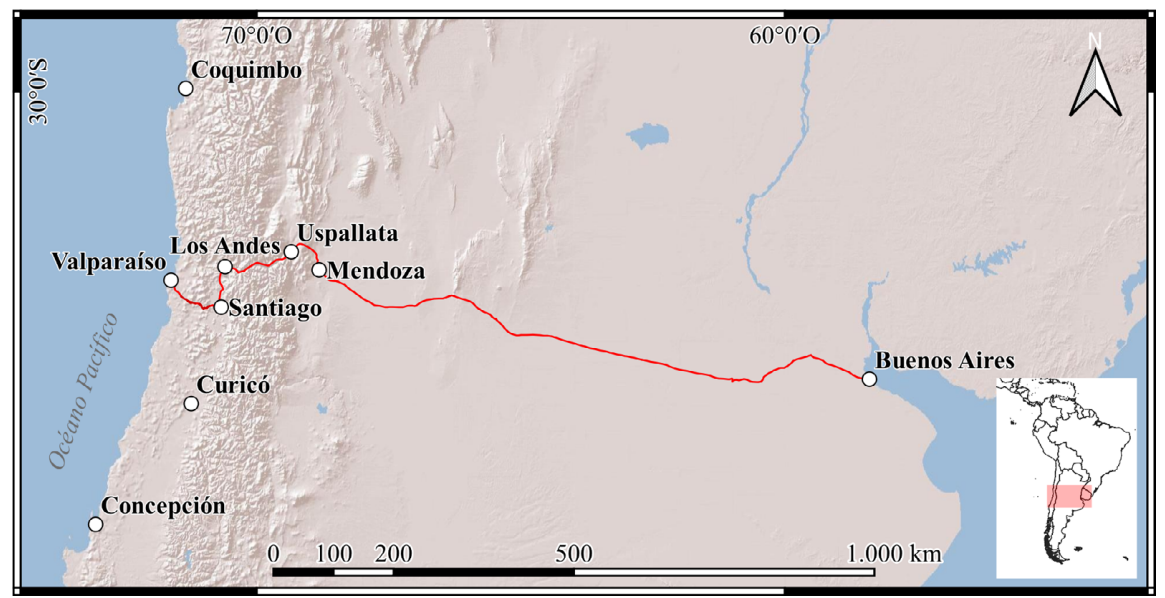

Fuente: Elaboración de José Manuel Lattus, 2021.

proyecto singular, sino de varias iniciativas solicitadas por distintos canales y momentos que apuntaron a reparar el camino y construir infraestructuras que garantizaran el paso durante el invierno. Algunas emanaron de actores locales, como los traficantes que veían afectados sus negocios. Por ejemplo, los vecinos de Aconcagua transmitieron las quejas de los arrieros y pasajeros a las autoridades santiaguinas, para que se repararan los malos pasos debido a lo «intransitable que se halla el camino» ${ }^{53}$ y porque este «se halla peligroso [...] de tal modo que el año pasado se perdieron nueve cargas que se rodaron al río». ${ }^{54}$ Este tipo de demandas se canalizaron a través de los cabildos y como los arreglos se ejecutaban vía remates, la Junta de Real Hacienda medió en estos asuntos, encargando inspecciones en terreno. ${ }^{55}$ En octubre de 1767, el corregidor y el cabildo de Mendoza confiaron estas diligencias a los

53 Juan Bautista Quiero, puentero del Aconcagua y administrador de la guardia de la cordillera, a Antonio de Guill y Gonzaga, Santiago, 14 de septiembre de 1767, ANH, Capitanía General, vol. 624, f. 1 .

54 Juan Bautista Jimenes a Antonio de Guill y Gonzaga, Santiago, 21 de octubre de 1767, ANH, Capitanía General, vol. 624, f. 4.

55 Decreto de la Junta de Real Hacienda de Santiago, 16 de octubre de 1767, ANH, Capitanía General, vol. 624, f. 3-3v. 
vecinos Jorge Cantero y Juan José Balderrama, quienes informaron detalladamente cuáles eran las zonas maltrechas y el tipo de reparaciones requeridas. Entre ellas, despejar las rocas del camino, ensanchar tramos angostos y levantar muros para contener cursos de agua y despeñaderos. ${ }^{56}$ Varias de estas medidas se realizaron luego de la adjudicación de la subasta, pero sería un error concluir que tanto estos como otros arreglos fueron los definitivos. ${ }^{57}$ Los temporales en la alta cordillera, los derrumbes y la nieve erosionaban la ruta provocando zanjas y desplazamientos de material en cada invierno, necesitándose repetidas intervenciones.

Por otro canal nació el proyecto de una infraestructura que asegurara el paso ininterrumpido de los correos para no quedar sujetos al tránsito estacional. Presentado a la corte en 1765 por el gobernador Antonio de Guill y Gonzaga y con la participación de Ambrosio O'Higgins como ingeniero delineador, contempló la construcción de seis refugios en la zona más elevada, los que servirían de albergue cuando el paso solía cerrarse por la nieve y las tormentas.$^{58}$ Hacia 1769 se habían construido cuatro casas, mientras que las dos restantes se concluyeron en el verano de 1772. A diferencia de la refacción del camino, esta iniciativa sobrepasó al ámbito local, ya que se refirió a las necesidades comunicacionales del imperio. El eje de la argumentación giró en torno al correo y la circulación de la información, sobre todo aquella que pudiera afectar al gobierno de las Indias. Frente a la escalada de extranjeros en los mares meridionales, si la cordillera estaba cerrada, «no podrían comunicarse por el gobierno a Buenos Aires, a este y el de Lima las noticias que allí se tendrían, pues siendo tan larga la vía de Potosí era regular que el mismo enemigo fuese el primer anuncio de su venida». ${ }^{59} \mathrm{El}$ cierre de la montaña implicaba un problema de orden estratégico. Las noticias debían llegar con regularidad para que los agentes gubernamentales pudieran

56 Acuerdo del cabildo de Mendoza, 16 de noviembre de 1767, ANH, Capitanía General, vol. 624, ff. 9-11. Informe de Jorge Cantero y Juan José Balderrama, Mendoza, 28 de noviembre de 1767, ANH, Capitanía General, vol. 624, ff. 12-17.

57 Otras inspecciones fueron solicitadas por la Junta de Real Hacienda de Santiago en 1769. El expediente completo de todas estas diligencias se encuentra en ANH, Capitanía General, vol. 624, ff. $1-53 v$.

58 O’Higgins calculó la distancia entre el valle de Aconcagua y Mendoza en 65 leguas y media, de las cuales 22 y media solo eran transitables a pie. Los refugios se construirían en ese tramo a distancias proporcionales entre sí en los siguientes parajes: Ojos de Agua, Alto de las Lagunas, la Cumbre, las Cuevas, Puente del Inca y Punta de Vacas. Estarían equipados con provisiones y funcionarían con un sistema de llaves entregadas en Mendoza y Santiago, cada vez que un correo saliera de cada ciudad. Ambrosio O'Higgins a Antonio de Guill y Gonzaga, Santiago, 29 de mayo de 1765, ANH, Varios, vol. 427, ff. 34-35.

59 Ibidem, ff. 32-33. 
reaccionar frente a eventos que pusieran en riesgo el dominio hispano. Sin embargo, cuando el proyecto se presentó los Borbones ya estaban preocupados de agilizar las comunicaciones del imperio. Las reformas del servicio postal a partir de 1764 diversificaron las rutas y Chile quedó supeditado a los itinerarios de la carrera ultramarina La Coruña-Montevideo-Buenos Aires. Desde allí la correspondencia se distribuía hacia Lima (vía Potosí) y Santiago (vía Mendoza-Aconcagua), por lo que el boquete debía mantenerse abierto durante todo el año para asegurar el flujo expedito de las comunicaciones, ya no solo con el Río de la Plata, sino también con Madrid. ${ }^{60}$ La formalización de este nuevo recorrido reforzó el valor político del paso de Uspallata, lo que se complementó con el aumento de las actividades mercantiles y militares en toda la región. Estas eran razones suficientes para que la construcción de los refugios y sus consecutivas reparaciones fueran respaldadas por la monarquía.

La ruta trasandina experimentó una nueva etapa desde 1790, pues la reparación del camino y los refugios dejaron de ir por vías independientes, reuniéndose en un plan integrado. Ambrosio O'Higgins, esta vez como gobernador, sometió a ambos a una compostura general bajo criterios profesionales. Hasta entonces, parte del mantenimiento del trazado se financiaba con dineros del pontazgo de Aconcagua, recaudados en la villa de San Felipe, y las casuchas corrían por cuenta del ramo de correos, administrado por Luis Villarroel mediante concesión y bajo la supervisión del conde de Floridablanca. ${ }^{61}$ No obstante, siguiendo sus facultades de intendente, O'Higgins canalizó las gestiones desde la gobernación y comunicó los avances directamente a los ministros de la corte, en busca del apoyo real. Esta dirección realzó la importancia de las obras y permitió que intervinieran elementos técnicos como mediciones geométricas y representaciones cartográficas a cargo de académicos e ingenieros militares, entre ellos, Antonio Martínez de Mata, Manuel de la Puente, Joaquín Toesca y Pedro Rico, quienes también participaron en el camino Santiago-Valparaíso. Esto significó un cambio respecto de la política local anterior, en que los arreglos del camino se sustentaron sobre la base de inspecciones encargadas por los cabildos a los vecinos. Los trabajos en ambas infraestructuras fueron dirigidos por Manuel de la

60 Sobre la aplicación de las reformas postales, José Araneda destaca que Chile se volcó hacia el Atlántico en términos comunicacionales por los nuevos recorridos establecidos y por la mayor frecuencia y regularidad en el flujo de la información. Araneda Riquelme, 2020, 95-112.

61 Real orden de 15 de febrero de 1790, ANH, Capitanía General, vol. 739, f. 35-35v. Contrata de administración de las casas de la cordillera, Santiago, 12 de mayo de 1772, ANH, Capitanía General, vol. 624, ff. 13-15. 
Puente e inspeccionados por Antonio Martínez de Mata, concluyendo en el verano de 1791. Las casas se repararon y el camino se ensanchó y enderezó. Se atenuaron las pendientes, quedando «franco, cómodo, seguro, y libre de riesgos» para los trajinantes y arrieros ${ }^{62}$ comunicándose todos los avances a los ministros y al superintendente de correos. Desde España se aprobaron las disposiciones del gobernador sin cuestionamientos y la Corona manifestó su apoyo incondicional a la obra: «expresa S. M. del acreditado celo de V. S. no perderá de vista esta obra importante así para adelantarla en lo que pueda faltar a su mayor perfección y solidez, como para atender a su conservación en lo sucesivo, acudiendo oportunamente al reparo de cualquiera ruina que ocasionen las avenidas o el transcurso del tiempo». ${ }^{63}$

La relevancia de esta obra también fue evidente para los científicos que cruzaron el paso esos años en el marco de la expedición Malaspina. Destacaron su utilidad para el arribo oportuno de las noticias y la sobrevivencia de los correos, en un paraje cuya vista «espantosa» no ofrecía más que «montañas sumamente quebradas, estériles y llenas de nieve». ${ }^{64} \mathrm{La}$ importancia estratégica del paso y toda la ruta intercontinental los llevó a plasmarlos en una de las pocas cartografías terrestres que realizó la expedición en Chile (Fig. 3) ${ }^{65}$

En las postrimerías del siglo el sistema postal se había consolidado en gran medida y los itinerarios a través de Uspallata adquirieron regularidad, ${ }^{66}$ por lo que los argumentos ya no giraban únicamente en torno al correo, sino al tránsito general. Por vía del despacho, Ambrosio O'Higgins destacó «las grandes ventajas que esto ha proporcionado al tráfico y comercio con este reino de los de esta América y España». ${ }^{67}$ Pese a mantener un

62 Ambrosio O’Higgins a Antonio Porlier, Santiago, 23 de octubre de 1791, ANH, Capitanía General, vol. 786, f. 16-16v.

63 Real orden del 29 de mayo de 1792, ANH, Capitanía General, vol. 741, f. 132. Directores de la Renta de Correos y Superintendente General a Ambrosio O'Higgins, Madrid, 9 de junio de 1790, ANH, Capitanía General, vol. 739, f. 142-142v.

64 José Espinoza y Felipe Bauzá, «Viaje de Santiago a Mendoza y noticias de esta última ciudad», en Sagredo y González, 2004, 880.

65 «Plano del Paso de Los Andes», levantado por Felipe Bauzá y José Espinoza y Tello en 1794. Forma parte de otro mapa de los autores, titulado «Carta esférica de la parte interior de la América meridional», Dirección Hidrográfica, 1810. Disponible en: http://www.bibliotecanacionaldigital.gob.cl/ bnd/631/w3-article-157393.html [Consultado: 12/08/2021].

66 Mientras que se logró una periodicidad de un barco cada dos meses entre La Coruña y Buenos Aires, la travesía Santiago-Buenos Aires llegó a dos veces al mes. Araneda Riquelme, 2020, 96 y 109.

67 Ambrosio O’Higgins a Antonio Porlier, Santiago, 23 de octubre de 1791, ANH, Capitanía General, vol. 786, f. 16. 
FIGURA 3

«PLANO DEL PASO DE LOS ANDES»

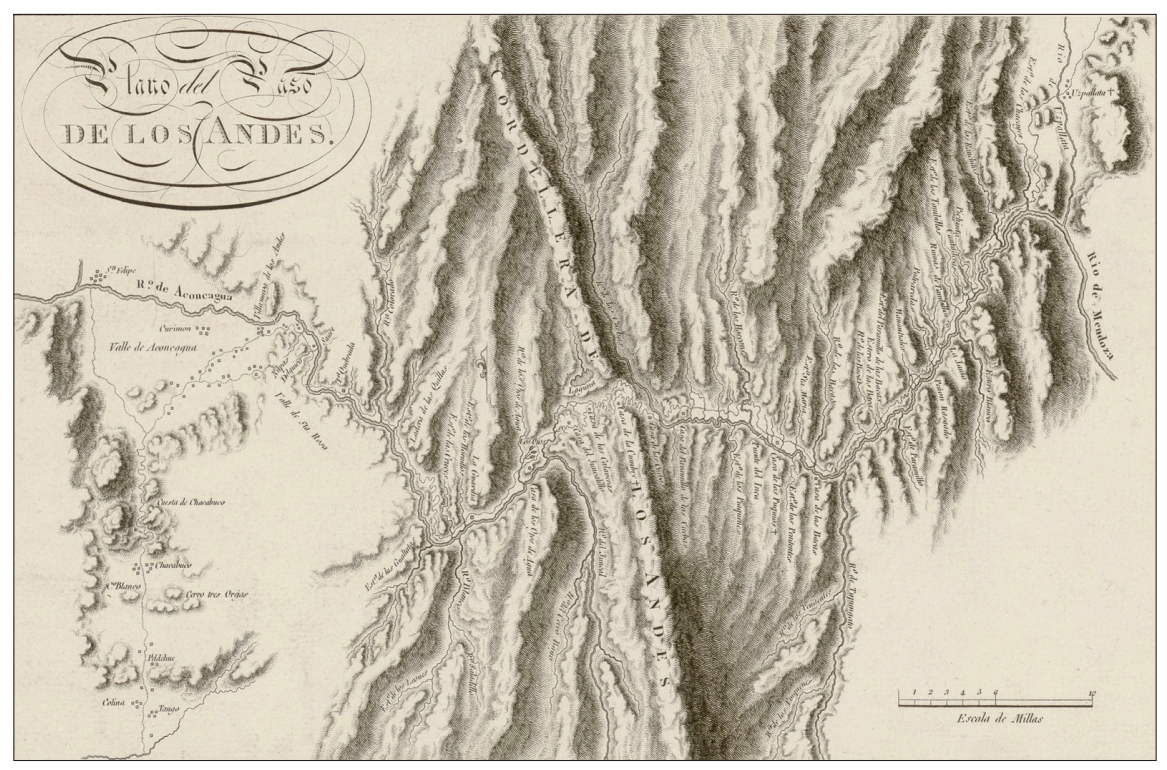

Fuente: «Carta esférica de la parte interior de la América meridional», Dirección Hidrográfica, 1810.

vínculo personal con la obra desde sus inicios, promover la vialidad fue uno de los sellos de su administración, la que supo vincular con otros propósitos gubernamentales, como la fundación de villas ${ }^{68}$ y el fortalecimiento de la colonización en territorios periféricos. Además, los conflictos internacionales y la amenaza inglesa reforzaban la importancia de mantener el contacto terrestre entre el Pacífico y el Atlántico sur. El corredor proporcionaba una buena opción para trasladar armamento y municiones que apoyaran la defensa de Buenos Aires desde Lima, vía Valparaíso, Santiago y Mendoza. ${ }^{69}$

68 La fundación de Santa Rosa de los Andes (1791) y San José de Maipo (1792) en parte respondieron a su locación en las rutas trasandinas de Uspallata y Portillo de Piuquenes, respectivamente.

69 La efectividad de la ruta para este tipo de operaciones se manifestó en 1797, cuando el virrey rioplatense, marqués de Sobremonte, solicitó apoyo a su par peruano ante el quiebre de las relaciones con Inglaterra. Esto se concretó con el envío de suministros que ascendían a 200 pares de pistolas, 1.500 espadas, 500 quintales de pólvora y 80 quintales de brea y alquitrán. Lacoste, 2009, 159-162. 
Finalizando el siglo XVIII, estrechar el contacto entre las capitales administrativas se complementó con la necesidad de lograr una mayor cohesión territorial del vasto continente sudamericano. Así, la política vial se extendió a buscar nuevos boquetes cordilleranos que permitieran establecer rutas transversales desde otros puntos del país hasta el Río de la Plata. Estos trazados adquirieron otro significado en la Frontera araucana. Abrir pasos trasandinos en una zona de dominio indígena ayudaría a asegurar la presencia hispana y someter a los naturales a una vida civilizada, mediante la introducción del comercio, el trabajo y la industria, convirtiéndolos en vasallos útiles. Estas consideraciones fueron expresadas por Ambrosio O'Higgins a los ministros durante las negociaciones hispano-mapuche en 1793, pero, en vista de su relevancia geopolítica, se determinó que se resolvieran en conjunto con el virrey rioplatense. ${ }^{70}$ En los albores del siglo XIX, expediciones como las de Santiago de Cerro y Zamudio, Sourryère de Souillac, Justo Molina Vasconcelos y Luis de la Cruz formaron parte de estas iniciativas realizadas desde Chile y Buenos Aires. ${ }^{71}$ Contando con el aval de funcionarios y comerciantes, el foco estuvo puesto en evaluar sus ventajas y condiciones para el tránsito carretero. Más aún, se pretendió dejar constancia de ellos para el conocimiento de las autoridades, en un momento en que la toma de decisiones sobre la base de evidencia empírica fue esencial para el buen gobierno y ejercer un control efectivo sobre los territorios.

La atención dada al paso de Uspallata, y a las rutas cordilleranas en general, respondió tanto a los ideales ilustrados de eficiencia administrativa, como a las necesidades geopolíticas del imperio. Los trabajos que

70 En 1793 se pidió al capitán general y al virrey rioplatense una relación detallada sobre la situación de las regiones fronterizas y que propusieran de forma unánime los medios para establecer las comunicaciones entre ambos reinos «por los países de los mismos indios». En agosto de 1794, O’Higgins indicó al virrey Nicolás de Arredondo que lo más conveniente era trazar una ruta directa desde Buenos Aires a Villarrica «por las mismas sendas y lugares que por donde en otros tiempos estuvo corriente el tráfico». Añadió haber corroborado la existencia de dicho camino a través de documentos y le solicitó enviar exploraciones que lo reconocieran en su jurisdicción. En septiembre de 1795 se reiteró la ordenanza de 1793, a la que O'Higgins contestó que no había recibido respuesta de parte del virrey. Real orden del 1 de octubre de 1793, ANH, Capitanía General, vol. 742, ff. 204-205v. Ambrosio O’Higgins a Nicolás de Arredondo, Santiago, 14 de agosto de 1794, ANH, Sergio Fernández Larraín, vol. 25, pieza 51. Real orden del 16 de septiembre de 1795, ANH, Capitanía General, vol. 744, ff. 212-213v.

71 Encargadas por el consulado bonaerense y con la venia del virrey marqués de Sobremonte, las expediciones de Cerro y Zamudio y Sourryère de Souillac (1802 y 1805) revelaron los pasos de El Planchón y Las Damas en la zona central de Chile, posibilitando el acceso a las ciudades de Curicó y Talca. En cambio, los viajes de Justo Molina (1798, 1799 y 1804) y Luis de la Cruz (1806) por los pasos de Alico y Antuco contaron con el apoyo del cabildo y la intendencia de Concepción, así como del gobernador de Chile y el virrey rioplatense. Véanse Angelis, 1837, vols. I y VI; Mollo y Della Mattia, 2009. 
se realizaron en la vía Santiago-Mendoza y su consolidación como eje trasandino no se explican sin el auge comercial de la costa sur-atlántica y la emergencia de Buenos Aires como nodo del nuevo sistema postal. Con ello, la vialidad transcontinental dejó de circunscribirse a iniciativas extraordinarias que quedaban en el ámbito de lo local, para insertarse dentro de un programa que incorporó las ideas que se venían gestando en Europa desde comienzos de siglo. Lograr una mayor integración económica y territorial de los dominios meridionales para el gobierno efectivo marcó el tono de las rutas trasandinas.

\section{El camino de Valdivia a Chiloé (1786-1793)}

Entrar en los territorios que se habían perdido a fines del siglo XVI marcó la pauta de este camino. ${ }^{72}$ La extensa región entre Valdivia y el canal de Chacao se mantuvo sin presencia española estable, hasta que comenzaron a ejecutarse los planes por recuperarla en los últimos decenios del siglo XVIII. Hasta entonces, el presidio y plaza fuerte de Valdivia y el archipiélago de Chiloé permanecieron como enclaves militares aislados que solo podían comunicarse entre sí y con el resto de los territorios por mar, relegados a precarias condiciones de vida y vulnerables frente a ataques indígenas y extranjeros. ${ }^{73}$

La reapertura de este camino también surgió de instancias locales. La idea era de larga data y contemplaba tomar posesión de las tierras circundantes, donde se encontraban las ruinas de la ciudad de Osorno, abandonada en 1603. Por más de un siglo los isleños quisieron expandirse hacia esa zona del continente. Los terrenos eran fértiles para el cultivo y la cría de ganado, lo que significaba una oportunidad para revertir el abandono y

72 El alzamiento de Curalaba de 1598 provocó la pérdida de las ciudades fundadas al sur del río Biobío, estableciéndose un territorio fronterizo de dominio indígena que sufrió pocas alteraciones hasta la segunda mitad del siglo XIX. Conocida como la «Frontera araucana», correspondió a la parte norte de una región más vasta que se extendía hasta Maullín y Carelmapu, colindantes con el canal de Chacao que separa al continente del archipiélago de Chiloé. La parte meridional de dicha franja, que media entre el archipiélago y Valdivia, es conocida como la «Frontera huilliche» o «Frontera de arriba». Es en esta zona en que se emplaza este proyecto vial.

73 Aunque la plaza de Valdivia se conectaba por vía terrestre con Concepción, se debía atravesar el territorio araucano bajo la autorización de sus caciques, haciéndola inestable. Las condiciones de navegación también eran difíciles entre Valdivia y Chiloé, siendo frecuentes los naufragios en la ruta. A su vez, los navíos que llegaban a ambos enclaves desde el Callao y otros puertos eran reducidos y esporádicos, siendo emblemático el caso de Chiloé, donde se limitaban a uno por año. Urbina Carrasco, 2009, 235-237. 
pobreza que los mantenía «acorralados», «en la opresión» ${ }^{74}$ y con «total falta y suma desdicha» ${ }^{75}$ Expresiones como estas fueron recurrentes a mediados del siglo XVIII para justificar ante las autoridades capitalinas la apertura del camino continental, sumándose argumentos defensivos y religiosos.

El aislamiento e incomunicación de ambos enclaves suponía un alto riesgo frente a invasiones extranjeras, acentuado por la preponderancia indígena en la región. ${ }^{76}$ Las incursiones por el mar del sur ya habían formado estragos hacia 1643 cuando Valdivia cayó en manos holandesas. Desde entonces, Valdivia y Chiloé ampliaron su poder defensivo con un sistema de fortificaciones que fue reforzado durante el XVIII. Aun así, debían reducirse las trabas logísticas que afectaban el buen funcionamiento de las operaciones militares, como contar con una vía alternativa que posibilitara la comunicación eficaz y segura con el resto de los territorios, la conducción de tropas y pertrechos para repeler ataques y posibles alianzas con los naturales. Para el gobernador de Chiloé, el camino era conveniente para su provincia, Valdivia y todo el continente, porque en caso de invasión se les daría un auxilio «más pronto, que el que se le pudiera dar de la frontera de la Concepción, pues en tres días pueda ser socorrida». ${ }^{77}$ Los alcances sobrepasaban la esfera local, ya que ambos enclaves fueron el primer resguardo de la América meridional luego de la travesía por el cabo de Hornos, asegurando las costas de Chile y Lima. A su vez, los fundamentos religiosos que amparaban la recuperación de los llanos de Osorno contribuían a legitimar la empresa. Por esta razón los vecinos de San Antonio de Chacao remarcaron que mediante la colonización «se efectúa la voluntad de nuestro monarca cuya católica intención es que en estos dominios se extienda el santo evangelio» ${ }^{78}$ Se trataba de una oportunidad para inculcar el ideal cristiano y las normas occidentales a los pueblos que allí habitaban, «desterrando el paganismo», sacándolos del «yugo de la ignorancia» y civilizando «las

74 Juan Antonio Garretón a Antonio de Guill y Gonzaga, Chacao, 21 de marzo de 1763, ANH, Capitanía General, vol. 694, f. 47.

75 Cabildo y vecinos de Castro, Castro, 20 de marzo de 1764, ANH, Capitanía General, vol. 694, f. 53.

76 Las relaciones pacíficas desarrolladas con los indios amigos en torno a Valdivia contrastaron con la parte meridional, colindante con Chiloé, que se caracterizaba por la enemistad con sus habitantes juncos y huilliches. Estas relaciones estuvieron mediadas por enfrentamientos bélicos ocasionales y ataques a algunos misioneros.

77 Juan Antonio Garretón a Félix de Berroeta, Chacao, 22 de octubre de 1762, ANH, Capitanía General, vol. 694, f. 43-43v.

78 Juan Antonio Garretón y vecinos de San Antonio de Chacao a Antonio de Guill y Gonzaga, Chacao, 26 de marzo de 1764, ANH, Capitanía General, vol. 694, f. 50-50v. 
almas de tanta nación bárbara que [...] se desentienden de toda obligación política y cristiana». ${ }^{79}$

Las tentativas por rehabilitar este paso terrestre comenzaron a materializarse cuando las regiones periféricas recibieron mayor atención y se reorganizó el régimen político territorial. Valdivia se erigió como un gobierno político-militar, adscrito a la intendencia de Concepción, pero dependiente de la capitanía general de Chile, mientras que Chiloé fue elevada en 1784 al rango de intendencia, subordinada al virreinato del Perú. Estas reformas incidieron no solo en la concreción misma de la obra por las competencias que se asignaban en materia vial, sino que también moldearon el desarrollo de los hechos, ya que las autoridades de ambos emplazamientos se disputaron la apertura del camino siguiendo sus propios planes y estrategias. ${ }^{80}$ En 1786, tanto el gobernador de Valdivia, Mariano de Pusterla, como el gobernador-intendente de Chiloé, Francisco Hurtado del Pino, retomaron la tarea. Este último fue autorizado por vía del despacho, así como por las instrucciones que recibió con el cargo de intendente.$^{81}$ Estas le instaban a formar caminos para facilitar la comunicación entre los pueblos, con el objeto de reducir a los naturales «al trato y sociedad de que carecen» y para que, en caso de peligro, «se reúnan con prontitud las tropas y milicias [...], y que todos los puestos se comuniquen los respectivos auxilios para su mutua conservación». ${ }^{82}$ Sin embargo, como las mismas instrucciones le encargaban no decidir nada en relación con los indios fronterizos, sin antes contar con el acuerdo del comandante de fronteras Ambrosio O'Higgins e informaciones provistas por el gobernador de Valdivia, el proceso estuvo mediado por un enredo administrativo y una lucha de poderes. ${ }^{83}$

Las exploraciones enviadas por Francisco Hurtado desde Chiloé en 1787 lograron encontrar el antiguo sendero, despejar la vegetación y dejar abierto el tránsito hasta las inmediaciones de Osorno. Divisaron sus ruinas a la distancia, pero los planes por ocuparla mediante una nueva expedición se interrumpieron por la destitución del intendente de su cargo. El proyecto

79 Ibidem, f. 50v.

80 El gobernador de Valdivia programó un avance hacia el sur a través de métodos pacíficos, mediante agasajos y misiones religiosas. En cambio, el intendente de Chiloé se dispuso a hacer lo propio en dirección al norte, pero mediante acciones bélicas y la construcción de fuertes. Más detalles sobre el desarrollo de los hechos y esta disputa jurisdiccional en Urbina Carrasco, 2005; 2009.

81 Ibidem, 2009, 266.

82 «Instrucción que debe observar el teniente coronel Don Francisco Hurtado, gobernador intendente de la isla de Chiloé, y adyacentes», art. 9, Aranjuez, 20 de mayo de 1784, ANH, Varios, vol. 427 , f. 46.

83 Ibidem, art. 18, f. 50 . 
quedó en manos de Mariano de Pusterla, quien pudo llevarlo a cabo con el apoyo del nuevo intendente interino de Chiloé, Francisco de Garos, y el ahora gobernador de Chile, Ambrosio O'Higgins (Fig. 4). En la avanzada desde Valdivia hacia el sur se establecieron misiones religiosas en Cudico y Daguipulli gracias a la intervención de Pablo Asenjo y, a fines de 1788, una expedición liderada por el sargento Teodoro Negrón logró atravesar todo este espacio fronterizo hasta su extremo meridional en Maullín y llegar a San Carlos de Chiloé. Una vez establecida la comunicación terrestre entre ambas plazas gracias a las negociaciones con los indios fronterizos, en 1791 se realizaron nuevos trabajos en la ruta, ensanchándola y construyendo puentes bajo la dirección del ingeniero Manuel Olaguer Feliú. El mismo año se hizo lo propio desde el sur, por encargo del gobernador de Chiloé. ${ }^{84}$

Pese a los progresos, la paz con los huilliches se quebró por una nueva insurrección en 1792, a lo que los hispano-criollos respondieron con el envío de tropas, propiciando el redescubrimiento de los vestigios de Osorno. A partir de ese momento, las intervenciones tomaron un nuevo curso. La política dirigida a franquear el camino se amplió hacia el restablecimiento de la ciudad, ejercer un dominio efectivo de la región y asegurar la presencia hispana de forma permanente. Ambrosio O'Higgins lideró las gestiones ante la corte, aunando ambos proyectos bajo un solo objetivo de control territorial que incluía planes de defensa - interna y exterior-, producción, comercio, evangelización y colonización. A la larga, estas medidas implicaban poner en práctica una estrategia de sujeción hacia los indígenas, basadas en la aplicación de un poder civilizatorio. ${ }^{85}$ O'Higgins, anteponiendo la utilidad y la felicidad pública, señalaba que la reducción de los naturales permitiría sacarlos del «estado de salvajes y gentiles en que se hallan, y acercarles a ser racionales y religiosos» $\gg{ }^{86}$ mientras que incentivarlos al trabajo y la agricultura era «el mejor medio de hacerles felices». ${ }^{87}$ Se trataba de convertirlos en «vasallos útiles de que se pueda esperar el engrandecimiento y felicidad de esta parte de los dominios de S. M.». ${ }^{88} \mathrm{El}$ camino, por lo tanto, formaba parte de esta estrategia de sujeción.

84 Juan Isidro Zapata, «Diario de la expedición del ensanche del camino de la Provincia de Chiloé a la Plaza de Valdivia», San Carlos de Chiloé, 24 de abril de 1791, ANH, Varios, vol. 276, ff. 139-179v.

85 Boccara, 2009, 199-301.

86 Ambrosio O’Higgins a Pedro Acuña y Malvar, Los Ángeles, 8 de enero de 1793, ANH, Capitanía General, vol. 786, f. 57.

87 Ambrosio O'Higgins a Pedro Acuña y Malvar, Santiago, 11 de febrero de 1794, ANH, Capitanía General, vol. 786, f. 81v.

88 Ambrosio O’Higgins a Diego de Gardoqui, Santiago, 31 de agosto de 1793, ANH, Capitanía General, vol. 786, f. 519v. 
Figura 4

REPRESENTACIONES CARTOGRÁFICAS ORIGINAL Y MODERNA

DEL CAMINO VALDIVIA-CHILOÉ
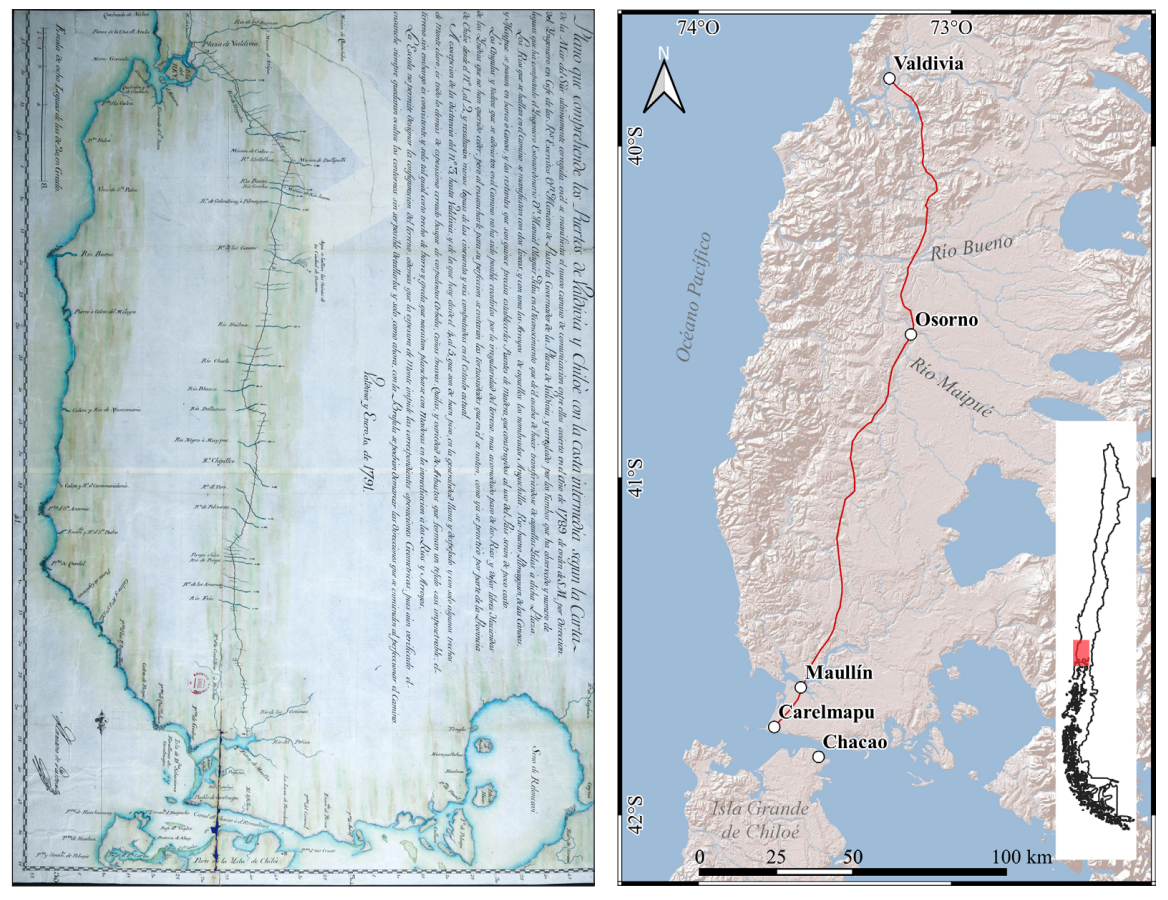

Fuente: Mariano de Pusterla, «Plano que comprehende los Puertos de Valdivia y Chiloé con la costa intermedia», Valdivia, 10 de enero de 1791, ANH, Mapoteca, 457 (izquierda). Elaboración de José Manuel Lattus, 2021 (derecha).

Su ubicación equidistante entre Valdivia y Chiloé convertía a Osorno en un puesto vital para la colonización y la mantención del camino fue el principal medio para lograr dichos propósitos. Este permitía unir y vertebrar el territorio, así como asegurar las posesiones australes del imperio. Los argumentos defensivos elevados por los chilotes años atrás se reiteraron, pues sin un contacto terrestre entre Valdivia y las islas de Chiloé «tendríamos que ver a los enemigos poseerlas tranquilamente sin poderles incomodar, porque sería imposible acercarnos a ellos privados del camino». ${ }^{89} \mathrm{El}$ control

89 Ambrosio O’Higgins a Pedro Acuña y Malvar, Los Ángeles, 8 de enero de 1793, ANH, Capitanía General, vol. 786, f. 56v. 
del extremo meridional se tornaba urgente considerando los antecedentes británicos en las islas Malvinas, pero también por las autorizaciones de pesca, navegación y comercio en el océano Pacífico. Después del conflicto de Nootka, en 1790 a las naves inglesas se les permitió el desembarco para comerciar con los indígenas y formar establecimientos temporales en «parajes no ocupados» por españoles..$^{90}$ Por ende, la soberanía hispana debía ejercerse mediante un dominio efectivo de sus territorios, más que con una mera posesión nominal. Para O'Higgins, solo reafirmando el tránsito por el camino se evitaría el contacto entre los extranjeros y los naturales, algo «que no sería de extrañar en unos tiempos en que se ha autorizado la libre navegación a estos mares». ${ }^{91}$

En 1793 quedó restablecido el tránsito terrestre entre Valdivia y la isla de Chiloé con un correo mensual. ${ }^{92}$ Las diligencias realizadas por Ambrosio O'Higgins fueron ampliamente aceptadas en la metrópoli. Se le facultó para que guiara personalmente la repoblación de Osorno y la completa reducción de la región, así como servir de mediador entre las opiniones e intereses de los gobernadores de Valdivia y Chiloé sobre el tema. ${ }^{93}$ Sin embargo, como el gobierno chilote estaba supeditado al virreinato del Perú, las acciones del capitán general se concentraron en el área valdiviana, es decir, hasta el río Maipué. ${ }^{94}$ Cuando se refundó Osorno en enero de 1796, pudo verificar el buen estado del camino, de 16 varas de ancho desde Valdivia, pero declaró que en el tramo desde Chiloé aún permanecían senderos sin ruta fija, por lo que instó al virrey a realizar mejoras a través del gobernador del archipiélago.95

La apertura del camino Valdivia-Chiloé sacó del aislamiento a ambas poblaciones y permitió la apropiación de esta franja de terreno, reafirmando la presencia española en un área que se había limitado a incursiones

90 «Convención concluida entre España é Inglaterra, transigiendo varios puntos sobre pesca, navegacion y comercio en el Océano Pacífico y los mares del Sur», 28 de octubre de 1790. Cantillo Jovellanos, 1843, 623-625.

91 Ambrosio O’Higgins a Pedro Acuña y Malvar, Los Ángeles, 8 de enero de 1793, ANH, Capitanía General, vol. 786, f. 56v.

92 Ambrosio O'Higgins a Pedro Acuña y Malvar, Santiago, 17 de septiembre de 1793, ANH, Capitanía General, vol. 786, f. 67v.

93 Real orden de 7 de diciembre de 1793, ANH, Capitanía General, vol. 742, f. 222.

94 La intendencia de Chiloé se suprimió en 1789, formándose un gobierno político-militar subordinado al virreinato peruano. Aunque limitaba al norte con el río Bueno, la refundación de Osorno significó la creación de una nueva jurisdicción (el partido de Alcudia), trasladándose el límite más al sur, hasta el río Maipué.

95 Ambrosio O’Higgins a Diego de Gardoqui, Osorno, 15 de enero de 1796, ANH, Capitanía General, vol. 786, f. 610v. 
misionales y militares esporádicas. El carácter fronterizo de este territorio lo hizo un espacio de conquista, por lo que la empresa brindó honores y reconocimientos formales a sus partícipes destacados. Las acciones de Mariano de Pusterla en 1788 le valieron el ascenso al grado de brigadier, mientras que a algunos de sus expedicionarios también se les promovió. ${ }^{96}$ Al sargento Teodoro Negrón se le otorgó el grado y sueldo de alférez, así como con la primera vacancia para optar a la subtenencia, y al teniente Pablo Asenjo se le concedió el de capitán. Pero no solo las intervenciones en esta zona fueron consideradas. Las obras viales para la Corona y sus ministros fueron apreciadas como un asunto de Estado, de modo que también se recompensó a Manuel de la Puente con el grado de coronel de milicias de Aconcagua, con el fuero correspondiente por los servicios prestados en el camino de Uspallata. ${ }^{97}$

\section{Conclusiones}

Sería un error concluir que los tres caminos aquí mencionados estuvieron desvinculados entre sí y que su análisis debe remitirse únicamente al plano local o a iniciativas personales. En efecto, los caminos SantiagoValparaíso, Valdivia-Chiloé y el paso trasandino surgieron desde instancias locales, pero el espaldarazo que recibieron de la Corona se basó en sus implicancias regionales y globales. Estos proyectos pudieron materializarse bajo un nuevo contexto intelectual y geopolítico, en donde mantener las posesiones de ultramar y estrechar la dependencia económica bajo los ideales ilustrados era imprescindible para el reposicionamiento de España como potencia internacional. El mayor control que se pretendía ejercer en las colonias americanas no se circunscribió únicamente al ámbito social o administrativo. También se consideraron elementos materiales para lograr dichos propósitos. El trazado de caminos permitía estrechar distancias, conectar mercados, cohesionar los espacios y facilitar la circulación de los agentes gubernamentales por el territorio. Esto hizo que recibieran una mayor determinación de parte de las autoridades peninsulares, siguiendo las pautas de fomento vial que ya se desarrollaban en Europa.

96 Real orden del 4 de abril de 1790, ANH, Capitanía General, vol. 739, f. 90-90v. Real orden del 20 de octubre de 1790, ANH, Capitanía General, vol. 739, f. 234-234v.

97 Real orden del 8 de julio de 1792, ANH, Capitanía General, vol. 741, f. 161. 
En parte, los proyectos chilenos lograron concretarse cuando la atención monárquica se volvió hacia los márgenes meridionales del imperio, con el fin de reforzar su dominio territorial y potenciar la extracción de sus recursos. Los nuevos circuitos comerciales y postales, así como el riesgo latente de invasión o contrabando en el Atlántico y Pacífico sur los validaron frente a la corte. Asimismo, la instauración de las intendencias reforzó este proceso en Chile. Ambrosio O'Higgins, más que gestor de las tres infraestructuras mencionadas, supo canalizar las demandas locales alineándolas con los intereses de la monarquía bajo argumentos de utilidad, felicidad pública y civilización, lo que contribuía a legitimar las empresas. Ello le valió el respaldo explícito y constante del rey y sus ministros, quienes veían a los caminos como un asunto de Estado. De esta manera, allanar las condiciones para el comercio, integrarse económica y políticamente con el espacio rioplatense y asegurar la colonización con fines estratégicos marcaron el tono de la política vial borbónica en Chile.

Recibido, 29 de abril de 2021 Segunda versión, 13 de agosto de 2021 Aceptado, 13 de septiembre de 2021

\section{Referencias bibliográficas}

Angelis, Pedro de, Colección de obras y documentos relativos a la historia antigua y moderna de las provincias del Río de La Plata, Buenos Aires, Imprenta del Estado, 1837.

Araneda Riquelme, José, Un gobierno de papel. El correo y sus rutas de comunicación en tiempos de la reforma imperial en Chile (1764-1796), Santiago de Chile, Ediciones de la Biblioteca Nacional/Centro de Investigaciones Diego Barros Arana, 2020.

Blond, Stéphane J. L., «The Trudaine Atlas: Government Road Mapping in Eighteenth-Century France», Imago Mundi, 65:1, Londres, 2013, 64-79.

Boccara, Guillaume, Los vencedores: historia del pueblo mapuche en la época colonial, San Pedro de Atacama, Línea Editorial IIAM, 2009.

Bogart, Dan, «Turnpike Trusts and the Transportation Revolution in $18^{\text {th }}$ Century England», Explorations in Economic History, 42:4, Cambridge, Massachusetts, 2005, 479-508.

Busch, Tracy Nichols, «Connecting an Empire Eighteenth-Century Russian Roads, from Peter to Catherine», The Journal of Transport History, 29:2, Reino Unido, 2008, 240-258. 
Cabildo de Santiago, Actas del cabildo de Santiago, vol. XXXV, en Colección de Historiadores de Chile y de documentos relativos a la historia nacional, t. LVIII, Santiago de Chile, Sociedad Chilena de Historia y Geografía/Academia Chilena de la Historia, 1990.

Cantillo Jovellanos, Alejandro del, Tratados, convenios y declaraciones de paz y de comercio que han hecho con las potencias estranjeras los monarcas españoles de la Casa de Borbón: desde el año de 1700 hasta el día, Madrid, Imp. de Alegría y Charlain, 1843.

Carmagnani, Marcello, Los mecanismos de la vida económica en una sociedad colonial. Chile 1680-1830, Santiago de Chile, Dibam/Centro de Investigaciones Diego Barros Arana, 2001.

Cavieres Figueroa, Eduardo, Servir al soberano sin detrimento del vasallo. El comercio hispano colonial y el sector mercantil de Santiago de Chile en el siglo XVIII, Valparaíso, Ediciones Universitarias de Valparaíso, 2003.

Crespo Delgado, Daniel, «Ingeniería civil e Ilustración en España», en Cámara Muñoz, Alicia y Revuelta Pol, Bernardo (eds.), Ingeniería de la Ilustración, Segovia, Fundación Juanelo Turriano, 2015, 35-47.

Donoso, Ricardo, El marqués de Osorno, don Ambrosio Higgins, 1720-1801, Santiago de Chile, Publicaciones de la Universidad de Chile, 1941.

Fernández de Mesa y Moreno, Tomás Manuel, Tratado legal, y politico de caminos públicos, y possadas, Valencia, España, Joseph Thomas Lucas, 1755.

Greve, Ernesto, Historia de la ingeniería en Chile, Santiago de Chile, Imprenta Universitaria, 1938, $4 \mathrm{v}$.

Guldi, Jo, Roads to power: Britain invents the infrastructure state, Cambridge/ Londres, Harvard University Press, 2012.

Jocelyn-Holt, Alfredo, La Independencia de Chile: tradición, modernización y mito, Madrid, Mapfre, 1992.

Kuethe, Allan J. y Andrien, Kenneth J., El mundo atlántico español durante el siglo XVIII. Guerra y reformas borbónicas, 1713-1796, Bogotá, Editorial Universidad del Rosario/Banco de la República, 2018.

Lacoste, Pablo, «Transporte terrestre en el Cono Sur (1550-1850): arrieros y troperos», Si Somos Americanos. Revista de Estudios Transfronterizos, IX:2, Iquique, 2009, 141-168.

Martínez, Pedro Santos, «Las comunicaciones entre el virreinato del Río de la Plata y Chile por Uspallata (1776-1810)», Boletín de la Academia Chilena de la Historia, 66, Santiago de Chile, 1962, 38-52.

Martínez, Pedro Santos, «Los caminos internacionales de la cordillera a mediados del siglo XIX (1852-1863)», Historia, 8, Santiago, 1969, 323-362.

Méndez Beltrán, Luz María, El comercio minero terrestre entre Chile y Argentina 1800-1840: caminos, arriería y exportación minera, Santiago de Chile, Universidad de Chile/Fondo de Publicaciones Americanistas, 2009. 
Menéndez Pidal, Gonzalo, Los caminos en la historia de España, Madrid, Ediciones Cultura Hispánica, 1951.

Molina Verdejo, Ricardo, «El camino real entre Valdivia y Chiloé: Su restablecimiento hacia fines del siglo XVIII», Revista Austral de Ciencias Sociales, 4, Valdivia, 2000, 115-126.

Mollo, Norberto y Della Mattia, Carlos, «Expedicionarios chilenos por las pampas argentinas: Parajes, rastrilladas, etnias y políticas de integración», Sociedad de paisajes áridos y semi-áridos, 1:1, Córdoba, 2009, 209-223.

Ordenanza de 4 de julio de 1718 para el establecimiento, e instrucción de Intendentes, y para Tesorero General, Pagadores, y Contadores de los Exercitos, y Provincias por orden de su Magestad, Madrid, Juan de Aritzía, 1720.

Ordenanza de 13 de octubre de 1749 para el restablecimiento, é instruccion de Intendentes de Provincias, y Exercitos, Madrid, Imprenta de Manuel Fernández, 1749.

Paquette, Gabriel, «State-civil Society Cooperation and Conflict in the Spanish Empire: The Intellectual and Political Activities of the Ultramarine Consulados and Economic Societies, c. 1780-1810», Journal of Latin American Studies, 39:2, Cambridge, 2007, 263-298.

Pereira Salas, Eugenio, Historia del arte en el Reino de Chile, Santiago de Chile, Ediciones de la Universidad de Chile, 1965.

Pietschman, Horst, Las reformas borbónicas y el sistema de intendencias en Nueva España. Un estudio político administrativo, México D. F., Fondo de Cultura Económica, 1996.

Pinto Vallejos, Sonia, Vías y medios de comunicación en Chile durante el siglo XVIII: el camino de Santiago a Valparaíso y su tráfico, Santiago de Chile, Ediciones Departamento de Estudios Humanísticos, 1976.

Real Ordenanza para el establecimiento é instruccion de Intendentes de Exército y Provincia en el Virreinato de Buenos-Aires, Madrid, Imprenta Real, 1782.

Recopilacion de leyes de los Reynos de las Indias, Madrid, Julián de Paredes, 1681. Reguera Rodríguez, Antonio T., «Los “Apuntamientos” del Padre Martín Sarmiento sobre la construcción de la Red Radial de Caminos Reales en España», Llull: Revista de la Sociedad Española de Historia de las Ciencias y de las Técnicas, 22:44, Zaragoza, 1999, 475-506.

Sáenz Ridruejo, Fernando, «La Escuela de Caminos, Canales y Puertos», en Navascués Palacio, Pedro y Revuelta Pol, Bernardo (eds.), Ingenieros Arquitectos, Madrid, Fundación Juanelo Turriano, 2015.

Sagredo, Rafael y González, José Ignacio, La Expedición Malaspina en la frontera austral del imperio español, Santiago de Chile, Editorial Universitaria/Centro de Investigaciones Diego Barros Arana, 2004.

Sanhueza Benavente, María Carolina, Por los caminos del Valle Central de Chile: el sistema vial entre los ríos Maipo y Mataquito (1790-1860), Santiago de 
Chile, Ediciones de la Dirección de Bibliotecas, Archivos y Museos/Centro de Investigaciones Diego Barros Arana, 2018.

Sarmiento, Martín, «Apuntamientos para un discurso sobre la necesidad que hay en España de unos buenos Caminos Reales, y de su pública utilidad», en Valladares de Sotomayor, Antonio, Semanario Erudito, que comprehende varias obras inéditas, críticas, morales, instructivas, políticas, históricas, satíricas, y jocosas, de nuestros mejores autores antiguos, y modernos, tomo XX, Madrid, Blas Román, 1789.

Serrera, Ramón María, Tráfico terrestre y red vial en las Indias españolas, Barcelona, Lunwerg Editores, 1992.

Terán, Fernando de, «Movilidad, comunicaciones y riegos en el entorno del Madrid borbónico», en Roch, Fernando y Disdier, Jorge (eds.), Madrid y los Borbones en el siglo XVIII. La construcción de una ciudad y su territorio, Madrid, Consejería de Cultura, Deportes y Turismo de la Comunidad de Madrid, 1984.

Thomas, John, «Los proyectos del virrey O’Higgins», Revista Chilena de Historia y Geografía, XI:15, Santiago, 1914, 128-149.

Urbina Carrasco, María Ximena, «La frontera "de arriba" chilena y el camino de Chiloé a Valdivia, 1786-1788», Temas americanistas, 18, Sevilla, 2005, 70-92.

Urbina Carrasco, María Ximena, La Frontera de arriba en Chile colonial: interacción hispano-indígena en el territorio entre Valdivia y Chiloé e imaginario de sus bordes geográficos, 1600-1800, Valparaíso, Ediciones Universitarias de Valparaíso/Centro de Investigaciones Diego Barros Arana, 2009.

Ustáriz, Gerónimo de, Theorica y practica de comercio y de marina, Madrid, Imprenta de Antonio Sanz, 1742.

Valle Pavón, Guillermina del, «Antagonismo entre el Consulado de México y el virrey Revillagigedo por la apertura comercial de Nueva España, 1789-1794», Estudios de Historia Novohispana, 24, Ciudad de México, 2001, 111-137.

Valle Pavón, Guillermina del, «Articulación de mercados y la reconstrucción del camino México-Veracruz, vía Orizaba, a finales del siglo XVIII», en Oikión Solano, Verónica (ed.), Historia, nación y región, Zamora, Michoacán, El Colegio de Michoacán, 2007, vol. II, 437-460.

Villalobos R., Sergio, El comercio y la crisis colonial, Santiago de Chile, Editorial Universitaria, 1990.

Ward, Bernardo, Proyecto económico, en que se proponen varias providencias, dirigidas á promover los intereses de España, con los medios y fondos necesarios para su plantificacion, Madrid, Joachin Ibarra, 1779. 